\title{
Improvement of roasted germinated brown rice flour processing using ergothioneine to limit oxidation during processing and preservation
}

\author{
${ }^{1}$ Truc, H.T., ${ }^{1}$ Trung, P.Q., ${ }^{1}$ Ngoc, N.T.L., ${ }^{1}$ Binh, N.D.T., ${ }^{2}$ Duy, L.N.D., ${ }^{1}$ Ngoc, T.T.A. and \\ ${ }^{1 *}$ Ha, N.C \\ ${ }^{1}$ Department of Food Technology, College of Agriculture, Can Tho University, 94000, Ninh Kieu, Can Tho, \\ Vietnam. \\ ${ }^{2}$ Department of Food Technology, Faculty of Chemical Engineering, Ho Chi Minh City University of \\ Technology, 72500, Ho Chi Minh, Vietnam.
}

\begin{abstract}
Article history:
Received: 2 May 2020

Received in revised form: 25

August 2020

Accepted: 10 January 2021

Available Online: 17 January 2021
\end{abstract}

\section{Keywords:}

Ergothioneine,

Enoki mushroom,

$\gamma$-aminobutyric acid,

Flammulina velutipes

DOI:

https://doi.org/10.26656/fr.2017.5(S1).032

\begin{abstract}
Roasting temperature and time are important parameters in the process of roasted germinated brown rice flour (RGBRF), which cause the loss of bioactive ingredients and sensory value of the product. During roasting and storage, fat oxidation is also one of the problems that reduce the quality of RGBRF. In order to complete the RGBRF process, experiments using different temperature and time as $160^{\circ} \mathrm{C}, 200^{\circ} \mathrm{C}, 240^{\circ} \mathrm{C}$ for 10 to 30 mins were done to find the best roasting conditions. To limit the oxidation of fat during the processing and preserving RGBRF, ergothioneine (ERG) extract from enoki mushroom were supplemented at $3 \%, 5 \%, 7 \%$ and $10 \%(\mathrm{w} / \mathrm{w})$ before roasted, the product was then ground and put into two types of packaging (PA and aluminum), vacuum seamed and stored at room temperature for 8 weeks were carried out. The results showed that germinated brown rice (GBR) which supplemented 3\% of the extract before roasted at $200^{\circ} \mathrm{C}$ for 30 mins showed the best quality in term of sensory value, $\gamma$-aminobutyric acid (GABA) content and helped to limit fat oxidation as well as maintained stable quality after 8 weeks of storage in PA and aluminum packaging. In addition, the results from in vitro of starch resistance and in vivo of sugar absorption capacity in rats showed that RGBRF did not significantly change the GI index as well as the ability to absorb sugar compared to unroasted product. The results indicated that RGBRF should be used as a nutritious food with the ability to supplement bioactive compounds to the people at risk of lifestyle diseases.
\end{abstract}

\section{Introduction}

Rice (Oryza sativa L.) is one of the major food ingredients in the world. Vietnam is one of the leading countries in the world in exporting rice but the income of farmers is not high, the price of products sold is lower than many other countries such as Thailand, India and the United States. However, the impact of climate change on agriculture and food security are posing serious threats to rice production and also are detrimental for the farmers (Dabi and Khanna, 2018). Therefore, processing rice into a value-added products increases costs, the market and raises income for farmers. Germinated brown rice (GBR) have become popular and enhance bioactive compounds such as fiber, gammaaminobutyric acid (GABA), gamma-oryzanol (GORY), ferulic acid and good for health (Wu et al., 2013; Cho and Lim, 2016). Functional compounds in GBR help to promote physiological effects like blood pressure regulation, reductions in obesity and blood cholesterol level (Dong and Seung, 2016). In 2012, Imam et al. also reported the mechanisms for antidiabetic effects, antihyperglycemia, low insulin index, antioxidative effect, antithrombosis, hypocholesterolemia, and neuroprotective effects of GABA and GORY in GBR.

In recent years, serious food safety issues have begun to change the food industry as a worldwide trend. Most consumers tend to prefer foods that contain natural additives over those with artificial food additives. Therefore, the extraction of natural antioxidants from plants for food application is necessary to meet the needs of consumers. Mushrooms have been found to be a potential source of antioxidants. ERG is one of the most powerful antioxidants found in some fungal species and is present in high concentrations in enoki mushrooms 
(Ey et al., 2007). However, there is currently no research or report on determining the supplemental ERG content that helps limit fat oxidation in Vietnam. Since, IR50404 variety has good alum tolerance, good pest and disease resistance, so it is grown in alum areas in the Mekong Delta. Especially, the growing time is short (only 83-85 days), so this variety is suitable for flood-affected areas. This is also reported as one of suitable variety for GBR production (Le et al., 2014; Nguyen et al., 2016). Therefore, this study was conducted to understand the effect of temperature and roasting time on the quality of RGBRF from IR50404 and determine the appropriate dose of antioxidant from mushroom extract before roasting to help reduce oxidation in the preservation of the roasted rice flour. In vivo experiment was also conducted to understand how the RGBRF affect to normal as well as diabete rats.

\section{Materials and methods}

\subsection{Germinated brown rice preparation}

IR 50404 rice cultivars were provided by Cuu Long Rice Research Institute (CLRRI) in Cantho city, Vietnam. The paddies were milled in Yanmar ST 50 miller. Brown rice was steeped in soaking solutions at buffer $\mathrm{pH} 4.0\left(\mathrm{Na}_{2} \mathrm{HPO}_{4} \cdot 12 \mathrm{H}_{2} \mathrm{O}\right.$ and citric acid) and $0,6 \%$ glutamic acid. The ratio of grain to the solution was $1: 3(\mathrm{w} / \mathrm{v})$. The soaking time was 6 hours at room temperature $\left(30 \pm 2^{\circ} \mathrm{C}\right)$. After 6 hours, the rice was taken and then wrapped in a cloth to maintain the moisture and left in the incubator $\left(37 \pm 1^{\circ} \mathrm{C}\right)$ for $24 \mathrm{hrs}$ (Nguyen et al., 2016).

\subsection{Crude mushroom erothioneine extracts preparation}

Crude mushroom erothioneine (ESH) extract was prepared by adapting our previously developed procedure. The fruiting body or waste portion of the mushrooms was chopped to size from $0.2 \mathrm{~cm}$ to $0.4 \mathrm{~cm}$ and $100 \mathrm{~g}$ of the ground material was separately extracted with $500 \mathrm{~mL}$ water at $95 \pm 2^{\circ} \mathrm{C}$ in a $1 \mathrm{~L}$ glass round-bottom flask for $1 \mathrm{hrs}$. The supernatant was collected by centrifuging the boiled mixture at $3000 \times \mathrm{g}$ for 15 mins at $4^{\circ} \mathrm{C}$ and was then evaporated at $40^{\circ} \mathrm{C}$ in vacuo. The residue obtained was further extracted with $50 \mathrm{~mL}$ of $70 \%(\mathrm{v} / \mathrm{v})$ aqueous ethanol. The ethanolic solution was vortexed, left to $4^{\circ} \mathrm{C}$ refrigerator for 2 hours, subsequently centrifuged at $3000 \times g$ for $15 \mathrm{mins}$ at $4^{\circ} \mathrm{C}$. The supernatant was collected and evaporated at $40^{\circ} \mathrm{C}$ in vacuo to remove ethanol.

\subsection{Effect of temperature and time roasting on the quality of rice flours}

Germinated brown rice $(100 \mathrm{~g})$ were roasted by the coffee roaster (model: JMS-270, China) at $160^{\circ} \mathrm{C}, 200^{\circ} \mathrm{C}$, $240^{\circ} \mathrm{C}$ in $10 \mathrm{mins}, 20 \mathrm{mins}$ and $30 \mathrm{mins}$. The roasted rice is then finely ground ( 3 times, $30 \mathrm{~s}$ per each) by the grinder (model: $1000 \mathrm{~g}$ mulry function disintegrator ST20B, China). The temperature and time roasting that gave the highest GABA content and sensory properties were chosen for further study.

\subsection{Effect of the extract added before roasting germinated rice on the quality of rice flours}

Germinated brown rice will be supplemented with $3 \%, 5 \%, 7 \%$ and $10 \%(\mathrm{w} / \mathrm{w})$ of the mushroom extract before roasting. The roasted rice was finely ground (3 times, $30 \mathrm{~s}$ per each) by the grinder (model: $1000 \mathrm{~g}$ mulry function disintegrator ST-20B, China), packed in alumium bags, and then kept in a room temperature $\left(30 \pm 2^{\circ} \mathrm{C}\right)$ for 8 weeks.

\subsection{Determination of $\gamma$-aminobutyric acid (GABA) content}

GABA content was determined with the method of Banchuen et al. (2010). Approximately $1 \mathrm{~g}$ of ground germinated brown rice sample was weighted in plastic tubes and $9 \mathrm{~mL}$ of deionized water was added and the slurries were shaken for $1.5 \mathrm{hrs}$ at room temperature. Then, $1 \mathrm{~mL}$ of $3 \%$ (by volume) sulfosalicylic acid was added and the mixture were centrifuged at $10,000 \times \mathrm{g}$ during 10 mins. The supernatant $(100 \mu \mathrm{L})$ were mixed with $100 \mu \mathrm{L}$ of $100 \mathrm{mM} \mathrm{NaHCO}_{3}$ and $100 \mu \mathrm{L}$ of $4 \mathrm{mM} 4$ -dimethylaminoazobenzene-4-sulfonyl chloride acetonitrile solution. The mixture was heated at $70^{\circ} \mathrm{C}$ for 20 mins to effect derivatization. After that, $500 \mu \mathrm{L}$ of absolute ethanol were added. The sample was then filtered, and $0.5 \mathrm{~mL}$ of the filtrate were injected into Shimadzu HPLC (Japan), with C18 column $(3.5 \mu \mathrm{m} 4.6$ $\mathrm{x} 150 \mathrm{~mm}$ ). The HPLC was equipped with a UV-Vis photodiode array detector set at $465 \mathrm{~nm}$ wavelength. The mobile phase was $25 \mathrm{mM}$ acetate buffer and acetonitrile (65:35) operated at the flow rate of $0.5 \mathrm{~mL} / \mathrm{min}$ at $55^{\circ} \mathrm{C}$. Pure GABA (Merck, Germany) was used as the standard for calibration.

\subsection{Determination of ergothioneine}

The ergothioneine (ESH) content in the extracts prepared from the fruiting body and waste was quantitatively determined by the method of Dubost et al. (2007) with a slight modification. Briefly, $1 \mathrm{~mL}$ of 1 mmol L ${ }^{-1}$ methimazole aqueous solution was added as an internal standard (IS) to $1 \mathrm{~mL}$ of the extracts, followed by extraction with $20 \mathrm{~mL}$ of $70 \%$ (final concentration) ethanol. The ethanolic solution was vortexed at $4^{\circ} \mathrm{C}$, subsequently centrifuged at $3000 \mathrm{x} g$ for 15 mins at $4^{\circ} \mathrm{C}$. The supernatant was collected and 
evaporated at $40^{\circ} \mathrm{C}$ in vacuum to remove ethanol. The ethanol free residue was dissolved in $10 \mathrm{~mL}$ deionized water. The analysis was carried out using a Shimadzu (Japan) high performance liquid chromatograph mass spectrometer equipped with a $\mathrm{C} 18$ reversed-phase column. The $100 \%$ deionized water was pumped as a mobile phase at a flow rate of $0.7 \mathrm{~mL} \min ^{-1}$. The injection volume of the sample was $10 \mu \mathrm{L}$ and the column temperature was kept at $50^{\circ} \mathrm{C}$. The $\mathrm{ESH}$ content was quantitatively determined by monitoring a peak area ratio (ESH/IS) of the fragment ions at $\mathrm{m} / \mathrm{z} 230$ and $\mathrm{m} / \mathrm{z}$ 115 for ESH and IS, respectively. A calibration curve was obtained by measuring the ESH standard of different concentrations.

\subsection{Determination of peroxide}

Peroxide value was determined by the method of AOAC (2000). Briefly, weighed $5 \mathrm{~g}$ of sample and put it into Erlen flask containing $25 \mathrm{~mL}$ of chloroform. It was shaken and kept for 5 mins at room temperature $\left(30 \pm 2^{\circ} \mathrm{C}\right)$. The mixture was then filtered and each $10 \mathrm{~mL}$ of the filtrate ws transferred to different Erlen flask and covered with a foil. Next, mixed the sample mixture with $0.6 \mathrm{~mL}$ of $0.1 \mathrm{~N} \mathrm{H}_{2} \mathrm{SO}_{4}$ and $5 \mathrm{~mL}$ of acetic acid. After that added $0.5 \mathrm{~mL}$ of saturated $\mathrm{KI}$ to the mixture in the flask, kept in dark for 15 mins. Thereafter, $30 \mathrm{~mL}$ of distilled water and $1 \mathrm{~mL}$ of $1 \%$ starch solution was added into the sample mixture and vortexed. $\mathrm{I}_{2}$ released from the mixture was titrated by $0.1 \mathrm{~N} \mathrm{Na}_{2} \mathrm{~S}_{2} \mathrm{O}_{3}$ solution to determine the peroxide value.

\subsection{Determination of color change}

Color was determined by using FRU (Model: WR10, China). The color was evaluated in terms of lightness $\left(\mathrm{L}^{*}\right)$, redness/greenness $\left(\mathrm{a}^{*}\right)$ and yellowness/blueness $\left(b^{*}\right)$.

\subsection{Principal component analysis (PCA) for sensory evaluation}

In this study, the principal component analysis (PCA) method was used to evaluate the sensory of the product (Lawless and Heymann, 1998). Firstly, the organoleptic properties of roasted germinated brown rice flour samples were initially proposed 12 sensory attributes for sensory evaluation such as flavor, aroma, color, and state (Table 1). Next, 10 panellists were trained to evaluate various attributes of the product, then evaluated 9 RGBR flour samples to select which attributes showed the specific properties of the product. So, the compact attributes of the product were determined. After that, the panellists were asked to rate the product sample by rating the attributes according to the intensity of the occurrence of that attribute following a qualitative descriptive analysis (QDA) method from 0 (none) to 5 (extremely). At the same time, the panellists were asked to rate the overall quality of the product samples with the following scales: very good (5 points), good (4 points), fair ( 3 points), average ( 2 points), poor ( 1 point) and very poor ( 0 points). PCA was done using the XLSTAT version 2018.1 software.

Table 1. Sensory attribute frequency of roasted germinated brown rice flour

\begin{tabular}{cccc}
\hline $\begin{array}{c}\text { Sensory } \\
\text { criteria }\end{array}$ & Attribute & Frequency & $\begin{array}{c}\text { Compact } \\
\text { attributes }\end{array}$ \\
\hline \multirow{2}{*}{ Color } & White & 1 & - \\
& Brown & 6 & $\mathrm{x}$ \\
\hline \multirow{4}{*}{ Aroma } & Roasted rice & 8 & $\mathrm{x}$ \\
& Rice flour & 6 & $\mathrm{x}$ \\
& Germinated brown rice & 1 & - \\
\hline \multirow{2}{*}{ State } & Rancid & 0 & - \\
\hline \multirow{5}{*}{ Flavor } & Deposit & 5 & $\mathrm{x}$ \\
& Viscosity & 9 & $\mathrm{x}$ \\
\hline & Sweetness & 6 & $\mathrm{x}$ \\
& Metaly & 0 & - \\
\hline \multirow{2}{*}{ secterness } & 3 & $\mathrm{x}$ \\
\hline
\end{tabular}

$\mathrm{x}$ : selected attributes, -: removed attributes

\subsection{Postprandial glucose by glucose tolerance test (GTT) in vivo}

GTT was determined using the method by Dura (2016). Four mice males, age 6-8 week, 25-30 g ideal weight with fasting for 4 hours and measured the glucose blood before testing. Sample $(0.2 \mathrm{~mL})$ was pumped directly into the esophagus and blood glucose determination at $0,15,30,60,120$ mins by ACCU Check Active (ROCHE, Germany). The samples and experiments were administered using a $4 \times 4$ Latin square design. Recorded results and blood glucose units are calculated according to Joslin Diabetes Center (2019).

\subsection{Blood plasma biochemical and antioxidant activity} in vivo

Normal male mice and type 2 diabetes mice were received from Institute of Vaccine and Medical Biologicals, Vietnam (IVAC). Both of them were housed in an environmental controlled room $\left(30-32^{\circ} \mathrm{C}, 65-75 \%\right.$ relative humidity) and mice was eaten with a chow diet (crude protein: 23\%; crude fat: $8 \%$; crude fiber: $4 \%$; moisture: $10 \%$ ) for healthy maintenance for one week before using for experiment set up. There were three animals per cage and six groups: Normal mice feeding with normal feed (control); Normal mice feeding with GBR roasting), type 2 diabetes mice feed with GBR; type 2 diabetes mice feed with roasted GBR; type 2 
diabetes mice feed with GBR and metformin, type 2 diabetes mice feed with roasted GBR and metfomin). The mice in the group using metformin were given hypoglycemic agents (Glucophage $500 \mathrm{mg}$ Tablets, 300 $\mathrm{mg} / \mathrm{kg}$ BW) and pump $0.2 \mathrm{~mL}$ directly into the esophagus after 2 hours fed with sample test. Feeding lasted for four weeks and the result recorded at every week. To check the blood plasma biochemical and antioxidant activity, total cholesterol, tryglycerides, HDL -C (High Density Lipoprotein Cholesterol), LDL-C (Low Density Lipoprotein Cholesterol), ALT (Alanine aminotransferase), AST (Aspartate transaminase) in blood, MDA (Malondialdehyde), GSH (Glutathione Reductase) in liver homogenates were determined with enzymatic methods using corresponding Ams Ellipse Automated Analyzer (AMS, Italy).

\subsection{Statistical analysis}

All experiments were carried out using 3 freshly prepared germinated roasted rice flour samples, $100 \mathrm{~g}$ for each sample and three replicates of each sample were analyzed. The results were statistically analyzed using one-way analysis of variance by Duncan multiple range test with mean square error at $5 \%$ probability calculated with the Statgraphic Centurion version 15 software.

\section{Results and discussion}

\subsection{Effect of temperature and time roasting on the colour} of GBR flours

Colour is an important quality factor that is directly related to the acceptability of food products. Roasting of rice at high temperatures changes in colour and taste due to caramel and melanoidin reactions. The change in roasted sprout rice colour is shown in Figure 1.

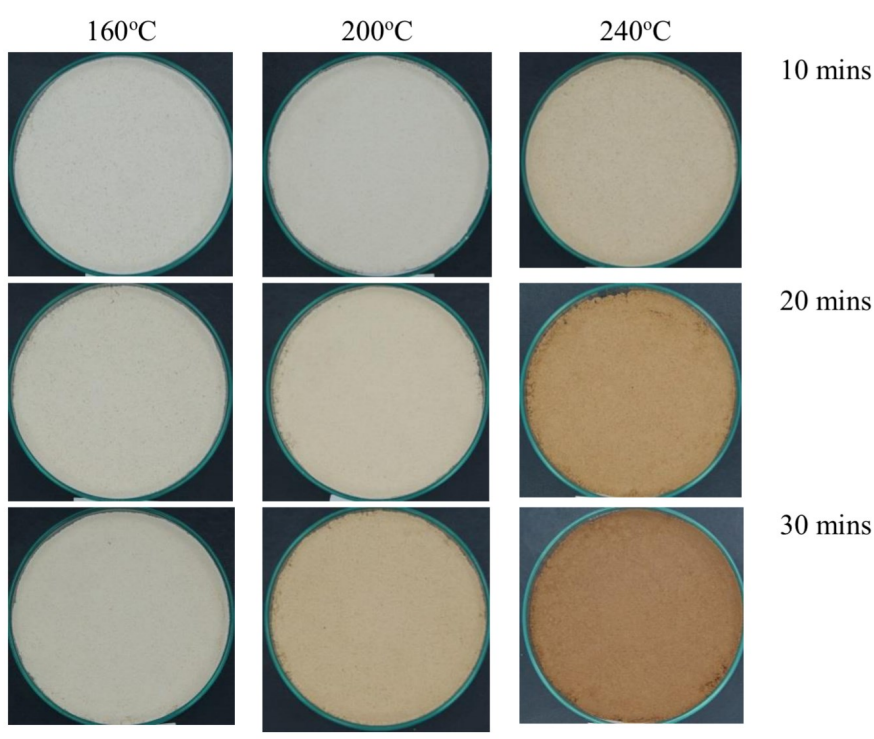

Figure 1. The appearance of RGBR flours according to various temperature and time
The roasting temperature has a significant effect on the colour rendition (through the $\mathrm{L}^{*}$ value) of roasted sprout rice flour (Figure 2). The brightness value $L^{*}$ of RGBR powder tended to decrease when the temperature increased from $160^{\circ} \mathrm{C}$ to $200^{\circ} \mathrm{C}$ and $240^{\circ} \mathrm{C}$ had a statistically significant difference $(\mathrm{p}<0.05)$. At the same time, the brightness value $L^{*}$ tends to decrease with statistical differences $(p<0.05)$ when roasting time is at 10 mins, 20 mins and 30 mins. This result is similar to Park et al. (2018) who studied the starch content and in vitro hydrolysis index of rice varieties containing inert starch, the value of $\mathrm{L}$ brightness of brown rice at a roasting temperature of $240^{\circ} \mathrm{C}$ for 30 mins is $68.5 \pm 0.5$. This result is consistent with the publication of Lee et al. (2003) who studied the effect of roasting conditions on the physical and chemical properties of rice flour.

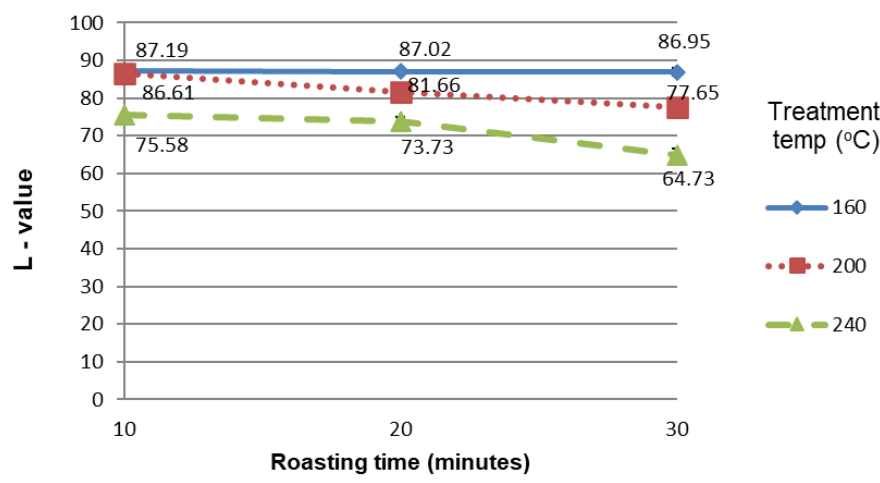

Figure 2. Colour values of RGBR flour according to various temperature and time

\subsection{Effect of temperature and time roasting on GABA content}

Figure 3 shows that the content of GABA decreases with temperature and roasting time. The results of the study are completely consistent with the announcement of Kwak (2010) who studied the time and temperature of roasted rice in GABA-rich brown rice production, specifically when roasted brown rice $(7.87 \mathrm{mg} / 100 \mathrm{~g})$ at $150^{\circ} \mathrm{C}$ for 20 mins, only $3.59 \mathrm{mg} / 100 \mathrm{~g}$ and when roasting $200^{\circ} \mathrm{C}$ for $10 \mathrm{mins}$, the GABA content is 2.72 $\mathrm{mg} / 100 \mathrm{~g}$ and when extending the roasting time to 16 mins, the content GABA decreased to $0.52 \mathrm{mg} / 100 \mathrm{~g}$.

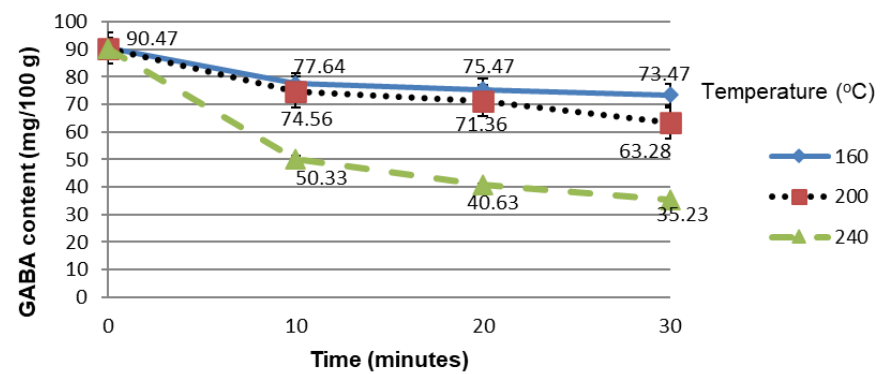

Figure 3. GABA content of RGBR flours according to various temperature and time

According to Dawson et al. (1959), GABA is a heat- 
stable amino acid, temperatures greater than $100^{\circ} \mathrm{C}$ without affecting GABA content. However, due to the reducing sugars, amino acids will participate in the Maillard reaction when exposed to high temperatures. Therefore, GABA content is lost mainly by the action of Maillard reaction.

\subsection{Effect of temperature and time roasting on sensory properties}

During roasting at different temperatures and times, the significant change in flavor was due to the reduction of sugars in the Maillard reaction and the breakdown of the strecker (amino acids) (Yaylayan, 2003). According to Garcia et al. (2012) fragrance developed during roasting, mainly due to the formation of Maillard reaction compounds. Moreover, among its end products is melanoidin, which is responsible for the color, aroma and antioxidant activity of many foods (Ramezanzadeh et al., 2000; Abdul-Hamid et al., 2007). Quantitative descriptive analysis methods allow the evaluation of the effect of roasting on the organoleptic properties of the product.

To describe the organoleptic properties of roasted germinated brown rice flour samples, 12 attributes were initially proposed for sensory evaluation such as color (white, brown), aroma (rice flour, roasted rice, germinated brown rice, rancid), state (viscosity, deposit), and flavor (sweetness, bitterness, astringency, metaly). Then, in order to select important attributes among them, sensory evaluation on 9 samples of roasted germinated brown rice were conducted by 10 panelists. As the result, eight sensory attributes with high frequency were chosen as brown, roasted rice, rice flour, viscosity, deposit, sweetness, astringency, bitterness (Table 1).

A graph of the distribution of roasted rice flour samples and sensory properties (Figure 4) shows the degree of dispersion of the sensory assembly and the relationship between roasted rice flour samples at temperatures $\left({ }^{\circ} \mathrm{C}\right)$ with different levels of time (mins). When roasted rice flour samples and sensory properties are shown on the same graph, roasted rice flour samples are located close to each other, they have similar sensory properties. The dispersion of the samples on the graph shows that changes in temperature and roasting time have a great influence on the sensory properties of roasted sprout rice.

The sample $200-30\left(200^{\circ} \mathrm{C}\right.$ in 30 mins $)$ and $240-10$ $\left(240^{\circ} \mathrm{C}\right.$ in $\left.10 \mathrm{mins}\right)$ were assessed as brown, with the typical aroma of roasted rice, with a high sensory point close to the brown attribute group, the smell of roasted rice and viscosity. Sample 240-20 were roasted at high temperatures and for a long time should be close to the bitter and acrid properties. In addition, the sample 160$20\left(160^{\circ} \mathrm{C}\right.$ in $\left.20 \mathrm{mins}\right), 160-30\left(160^{\circ} \mathrm{C}\right.$ in $\left.30 \mathrm{mins}\right)$ and $200-10\left(200^{\circ} \mathrm{C}\right.$ in $\left.10 \mathrm{mins}\right)$ dispersed very far from the remaining samples, demonstrating the This sample has little or no effect on the two main ingredients and attributes, and it has low sensory scores, in other words, roasting temperature and roasting time (mins). This model has a low sensory value and does not affect the main ingredient of the product.

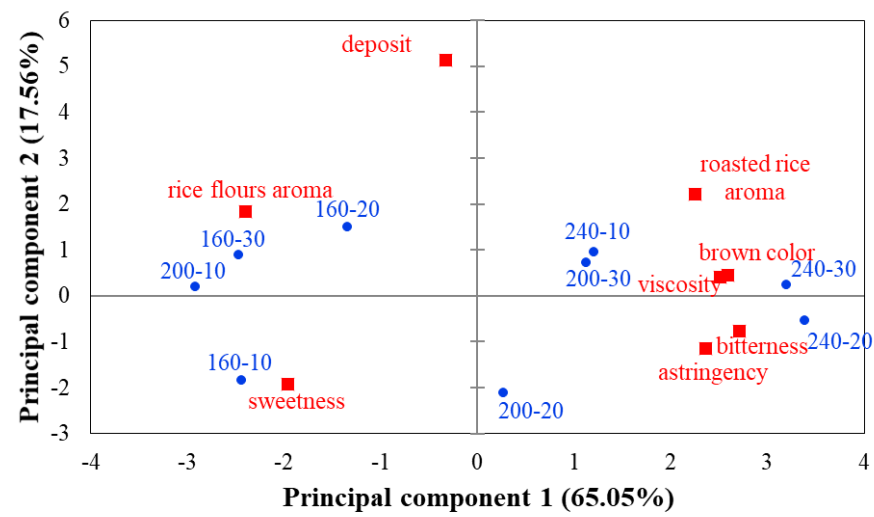

Figure 4. Principal component biplot of descriptive analysis of the nine germinated roasted rice flours samples

\subsection{The effect of the extract added before roasting germinated rice on color}

The color of germinated rice flour supplemented with acupuncture mushroom extract at a concentration of $0 \%, 3 \%, 5 \%, 7 \%$ and $10 \%$ before roasting at $200^{\circ} \mathrm{C}$ for 30 mins is shown in Figure 5.

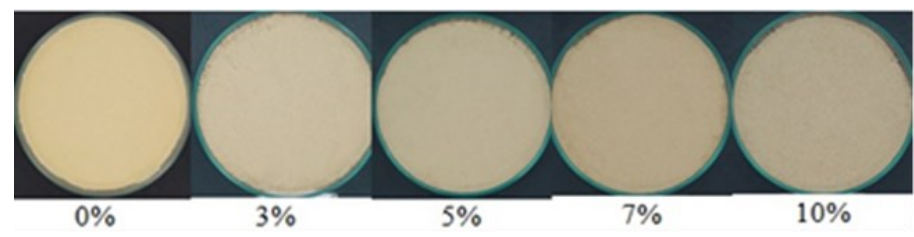

Figure 5. The effect of the extract added before roasting germinated rice on color according to various concentration

Figure 5 shows that the color of rice flour darkens with increasing acupuncture extract. This may explain that, during germination, some activated enzymes and some non-protein nitrogen substances such as nucleic acids increase the total protein content and ergothioneine is considered a free amino acid (Melville et al., 1955).

\subsection{The effect of the extract added before roasting germinated rice on the peroxide value}

Roasting inactivates enzymes responsible for oxidation (lipoxygenase and lipase) (Saunders, 1990). However, when the product has low humidity, the activity of the water is very small, the reaction rate of self-oxidizing fat (self-oxidation) increases. Water activity below 0.3 reaches the main adsorption zone, where water molecules can be linked to groups such as 
carboxyl $(\mathrm{COOH})$, linked to other water molecules by hydrogen bonding (Garcia et al., 2012). This layer of water will cover the food, but it will not dissolve food ingredients, which can lead to an increase in lipid oxidation. Therefore, it is necessary to add antioxidants before roasting to help preserve the quality and extend the shelf life of the product.

The results of Table 2 show that when supplementing with mushroom extract (containing Ergothioneine) in concentrations of $3 \%$ to $10 \%$, prevented fat oxidation significantly after 8 weeks of storage compared to samples without supplement with mushroom extract.

Table 2. The effect of the extract added before roasting germinated rice on the peroxide value $(\mathrm{mEq} / \mathrm{kg}$ lipid) according to various concentrations.

\begin{tabular}{cccccc}
\hline $\begin{array}{c}\text { Storage time } \\
\text { (weeks) }\end{array}$ & \multicolumn{5}{c}{ The extract concentration (\%) } \\
\cline { 2 - 6 } & 0 & 3 & 5 & 7 & 10 \\
\hline 0 & $0.26 \pm 0.01^{\mathrm{a}}$ & $\mathrm{NS}$ & $\mathrm{NS}$ & $\mathrm{NS}$ & $\mathrm{NS}$ \\
2 & $0.30 \pm 0.02^{\mathrm{b}}$ & $\mathrm{NS}$ & $\mathrm{NS}$ & $\mathrm{NS}$ & $\mathrm{NS}$ \\
4 & $0.36 \pm 0.03^{\mathrm{c}}$ & $\mathrm{NS}$ & $\mathrm{NS}$ & $\mathrm{NS}$ & $\mathrm{NS}$ \\
6 & $0.45 \pm 0.03^{\mathrm{d}}$ & $\mathrm{NS}$ & $\mathrm{NS}$ & $\mathrm{NS}$ & $\mathrm{NS}$ \\
8 & $0.98 \pm 0.09^{\mathrm{e}}$ & NS & NS & NS & NS \\
\hline
\end{tabular}

Values followed by the same letter within the same column are not significantly different from each other $(p>0.05)$. NS: not significant $(\mathrm{p}>0.05)$.

\subsection{The effect of the extract added before roasting germinated rice on ergothioneine content}

Ergothioneine is one of the most powerful antioxidants found in some fungal species and it is present in high concentrations (Ey et al., 2007). Results of analysis of Ergothioneine content after roasting at concentrations of the extract of acupuncture needles according to storage time are shown in Figure 6.

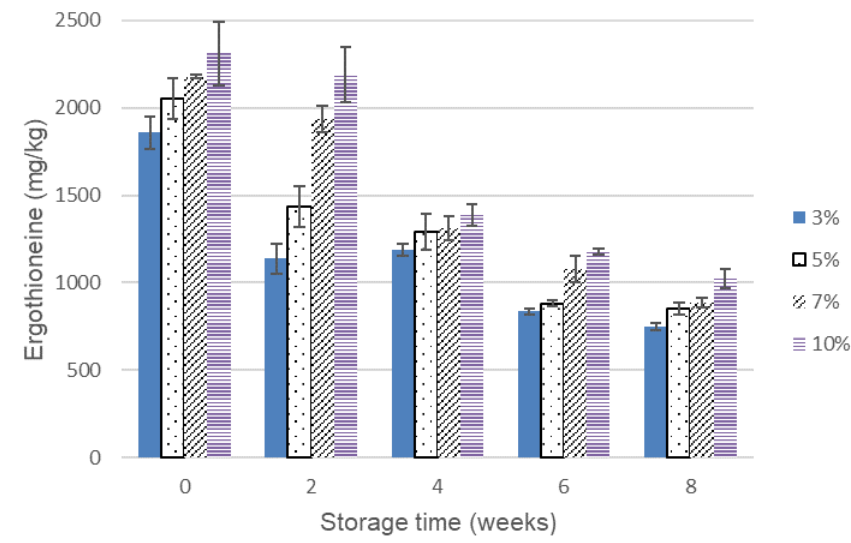

Figure 6. The effect of the extract added before roasting germinated rice on Ergothioneine content $(\mathrm{mg} / \mathrm{kg})$ according to various concentration
The analysis of Ergothioneine content in Figure 6 shows that the content of Ergothioneine at the levels of fungal extract concentration decreased with time of storage with statistical differences $(\mathrm{p}<0.05)$.

\subsection{Postprandial glucose by glucose tolerance test (GTT) determination in vivo}

Figure 7 shows the effect of RGBRF and GBR product to the normal rat group as well as the sick rat with or without using the metformin. The control sample and NM-RGBR suggests the retention of glucose blood through the weeks using the test sample. Although consuming food is similar for all groups, changes in plasma glucose reflect the effects of various dietary components given to different mouse groups and the rise and duration of hyperglycemia after a meal depends on its composition, i.e., quantity and quality of carbohydrate content (Rebolledo and Dato, 2005). The glycemic index in T2D-GBR group increased slower than T2D-RGBR group indicated that RGBR product could not help decreasing or stability strongly the GI in T2D mice comparing to GBR. This may due to GABA content decreased considerably when increased the temperature and the time of roasting (Figure 3). Imam et al. (2012) reported that white rice (WR) can be increased diabetic complications by diet. The glycemic index is reduced against the initial T2D-NS-M group and trending down next on week 3 and 4. Comparing to the T2D-GBR-M group, T2D-GBR without the use of metformin showed a negative effect to type 2 diabetic rat. And, when compared to the group of type 2 diabetes rat that was fed with GBR and RGBR, the result indicates that the roasting process may slightly affect the quality of the GBR product. There is no negative effect between RGBR and normal feed. Therefore, RGBRF should be used as a nutritious food with the ability to supplement

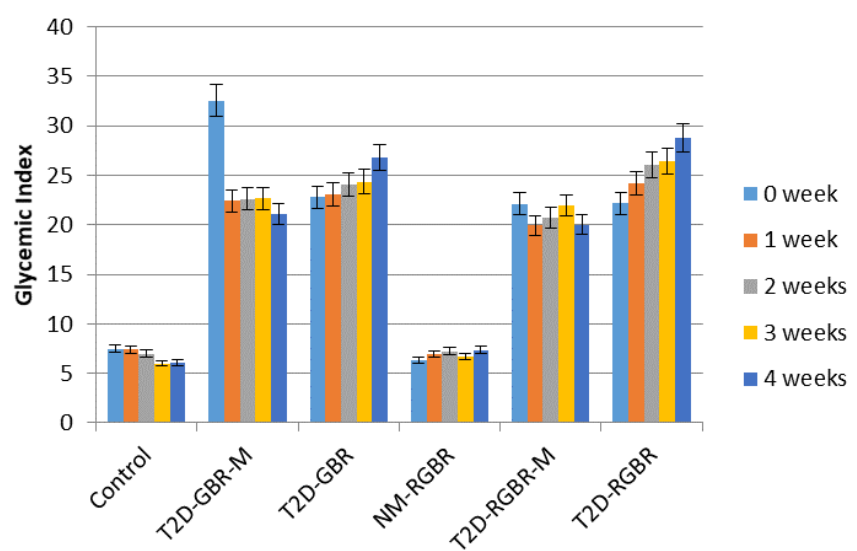

Figure 7. Glycemic index over four weeks of intervention. Control: normal mice feeding with normal feed, NM-RGBR: normal mice feeding with GBR roasting, T2D-GBR: type 2 diabetes mice feed with GBR, T2D-RGBR: type 2 diabetes mice feed with roasted GBR, T2D-GBR-M: type 2 diabetes mice feed with GBR and metformin, T2D-RGBR-M: type 2 diabetes mice feed with roasted GBR and metfomin. 
bioactive compounds to the people at risk of lifestyle diseases. This is not strong like a drug but similar to GBR, Since there are numerous studies that have also demonstrated health benefits of functional compounds available in GBR based flour (Imam et al., 2012)

\subsection{Blood plasma biochemical and antioxidant activity determination in vivo}

The results in Figure 8 show the biochemical components of blood plasma. The control and NMRGBR groups were the sample control. The results showed that diabetes complications still occurred from the increase in total cholesterol, triglycerides LDL-C ALT, AST, and a decrease in HDL-C in the T2D-RGBR group. This complication indicates that RGBRF does not exhibit diabetes inhibitory activity well. This may also be due to the decrease of GABA content caused by high temperature and longer roasting time (Figure 3 ). Besides, there were no significant differences $(\mathrm{P}<0.05)$ between the control group which fed with normal feed and NMRGBR group. This indicated that RGBRF affected positively to biochemical components of blood plasma of normal mice as well as diabetic mice.

GBR contains a variety of antioxidants that help decrease of hyperglycemia and dyslipidemia in the liver and fat tissue to diabetes complications (Imam et al., 2012; Dura et al., 2016; Govindarajan and Vellingiri,
2016; Wahjuningsih et al., 2018) and serves as protection against LDL oxidation and nutritional component degradation, such as dietary fibers, vitamins $\mathrm{B}$ and E, $\gamma$-oryzanol, and GABA ameliorate hypercholesterolemia and LDL-C (Minhajuddin et al., 2005; Roohinejad et al., 2009). GBR influences various physiological effects, such as blood pressure regulation, obesity, and blood cholesterol reductions, and GBR consumption by mice leads to a reduction in blood triglyceride concentration (Shallan et al., 2010; Mohd Esa et al., 2011; Imam et al., 2014; Dong and Seung, 2016). Besides, Mohd Esa et al. (2013) suggested that antioxidant activity resulting from GBR can significantly lower the activities of ALT and AST in the rabbit, that is, the effects of BR and GBR on liver enzymes, as well as serum antioxidant, can decrease diabetes complications.

\section{Conclusion}

GBR roasted at $200^{\circ} \mathrm{C}$ for 30 mins was the best roasting condition for RGBRF (in terms of sensory value and GABA content) in a $100 \mathrm{~g}$ batch. Supplemented 3\% ERG found in enoki mushroom extract to help prevent oxidation of RGBRF product. Adding 3\% mushroom extract before roasting would help to reduce fat oxidation and maintain a stable powder quality for 8 weeks of storage in aluminum bags. In vivo experiments indicate that RGBRF should be used as a nutritious food with the ability to supplement bioactive compounds to the people

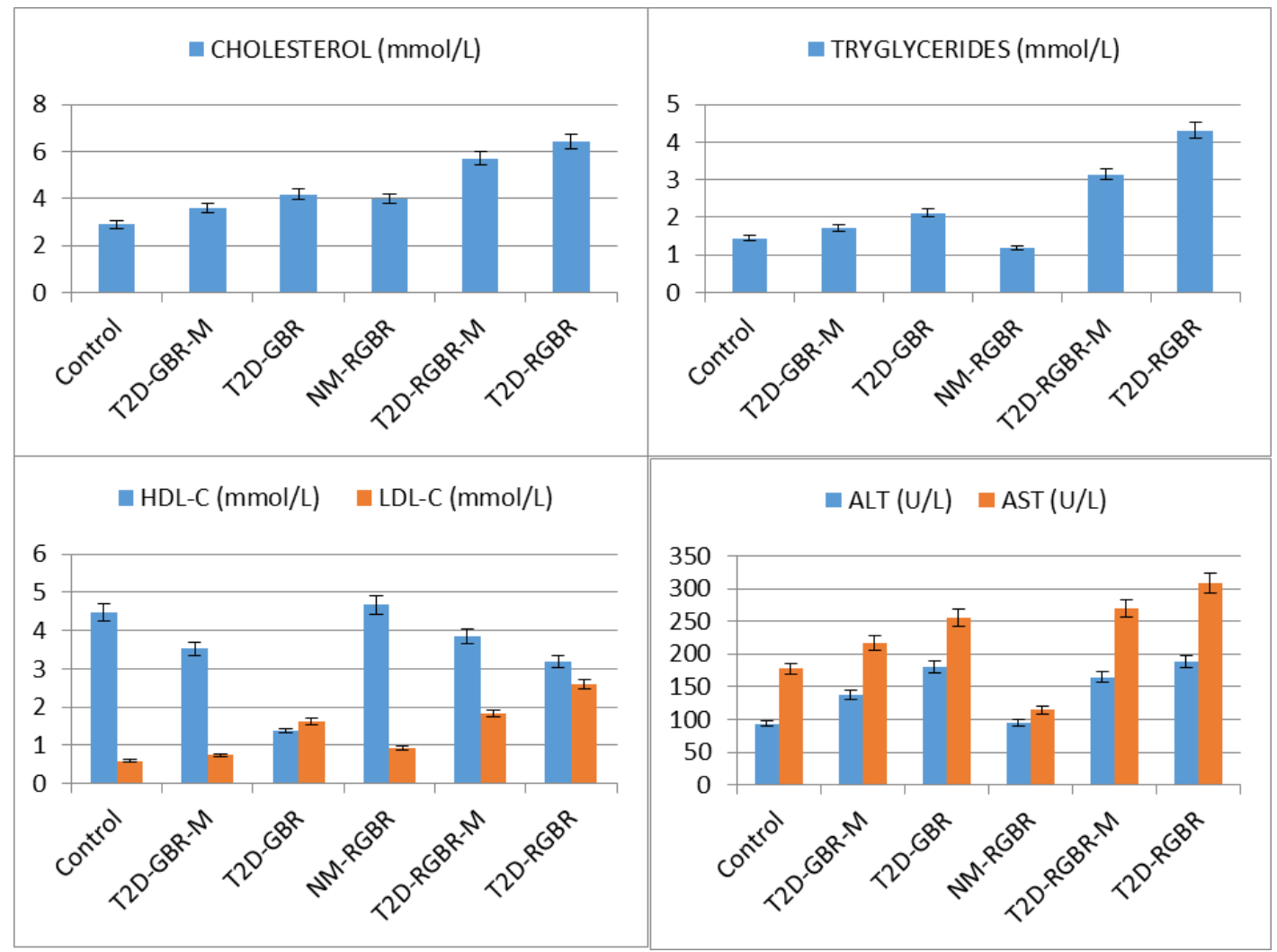

Figure 8. Blood plasma biochemical index and antioxidant activity. Control: normal mice feeding with normal feed, NM-RGBR: normal mice feeding with GBR roasting, T2D-GBR: type 2 diabetes mice feed with GBR, T2D-RGBR: type 2 diabetes mice feed with roasted GBR, T2D-GBR-M: type 2 diabetes mice feed with GBR and metformin, T2D-RGBR-M: type 2 diabetes mice feed with roasted GBR and metfomin. 
at risk of lifestyle diseases as diabetes, and cardiovascular disease.

\section{Acknowledgement}

This is funded in part by the Can Tho University Improvement Project VN14-P6, supported by a Japanese ODA loan, Program A15 and sponsored by the project "Optimization of processing of germinated brown rice flour", Department of Science and Technology, Can Tho City, Vietnam.

\section{References}

Abdul, A.H., Raja Sulaiman, R.R., Osman, A. and Saari, N. (2007). Preliminary study of the chemical composition of the rice milling fractions stabilized by microwave heating. Journal of Food Composition and Analysis, 20(7), 627-637. https:// doi.org/10.1016/j.jfca.2007.01.005

AOAC. (2000). Official Methods of Analysis of The Association of Official Analytical Chemists. Washington, D.C.: AOAC.

Banchuen, J., Paiboon, T, Buncha, O, Phaisan, W. and Piyarat, S. (2010). Increasing the bio-active compounds contents by optimizing the germination conditions of southern Thai Brown rice. Songklanakarin Journal of Science and Technology, 32(3), 219-230.

Dawson, R.M., D.C., Elliot, W.H., Elliot, K.M. (1959). Data for Biochemical Research, Oxford: Clarendon Press.

Dong, H.C. and Seung, TL. (2016). Germinated brown rice and its bio-functional compounds. Food Chemistry, 196, 259-271. https://doi.org/10.1016/ j.foodchem.2015.09.025

Dubost, N.J., Boxin, O. and Robert, B.B. (2007). Quantification of polyphenols and ergothioneine in cultivated mushrooms and correlation to total antioxidant capacity. Food Chemistry, 105(2), 727735. https://doi.org/10.1016/j.foodchem.2007.01.030

Dura, A., Yokohama, W. and Cristina M.R. (2016). Glycemic Response to Corn Starch Modified with Cyclodextrin Glycosyltransferase and its Relationship to Physical Properties. Plant Foods for Human Nutrition, 71, 252-258. https:// doi.org/10.1007/s11130-016-0553-6

Ey, J., Schömig, E. and Taubert, D. (2007). Dietary Sources and Antioxidant Effects of Ergothioneine. Agricultural and Food Chemistry, 55, 6466-6474. https://doi.org/10.1021/jf071328f

Garcia, M.C., Benassi, M.D.T. and Soares Junior, M.S. (2012). Physicochemical and sensory profile of rice bran roasted in microwave. Ciência E Tecnologia De Alimentos, 32, 754-761. https://doi.org/10.1590/ S0101-20612012005000097

Govindarajan, S. and Vellingiri, K. (2016). Effect of red yeast rice and coconut, rice bran or sunflower oil combination in rats on hypercholesterolemic diet. Journal of Clinical and Diagnostic Research, 10(4), $17-19$ JCDR/2016/18623.7624

Imam, M.U., Musa, S.N.A., Azmi, N.H. and Ismail, M. (2012). Effects of White Rice , Brown Rice and Germinated Brown Rice on Antioxidant Status of Type 2 Diabetic Rats. International Journal of Molecular Sciences, 13(10), 12952-12969. https:// doi.org/10.3390/ijms131012952

Joslin Diabetes Center (2019). Conversion Table for Blood Glucose Monitoring. Retrieved on October 30, 2019 from Joslin Diabetes Website: https:// www.joslin.org/patient-care/diabetes-education/ diabetes-learning-center/conversion-table-bloodglucose-monitoring.

Kwak, E.J. (2010). Development of Brown Colored Rice Tea with High GABA Content. Journal of the Korean Society of Food Science and Nutrition 39(8), 1201-1206. https://doi.org/10.3746/ jkfn.2010.39.8.1201

Lawless, H.T and Heymann H. (1998). Sensory Evaluation of Food: Principles and Practices. Chapman and Hall, New York, p 608.Le N.D.D and Nguyen, C.H. (2014). Influence of soaking and germination conditions on the $\gamma$-aminobutyric acid (gaba) content of 2 rice varieties (IR 50404 and Jasmine 85) from mekong delta. Journal of Science and Development,12(1), 59-64.

Lee, G.C., Kim, S.J. and Koh, B.K. (2003). Effect of Roasting Condition on the Physicochemical Properties of Rice Flour and the Quality Characteristics of Tarakjuk. Korean Journal of Food Science and Technology, 35(5),905-913.

Melville, D.B., Otken, C.C. and Kovalenko, V. (1955). On the origin of animal ergothioneine. Journal of Biology Chemistry, 216(1), 325-331. https:// doi.org/10.1016/S0021-9258(19)52309-2

Mohd Esa, N., Abdul Kadir, K.K., Amom, Z. and Azlan, A. 2011. Improving the lipid profile in hypercholesterolemia-induced rabbit by supplementation of germinated brown rice. Journal of Agricultural and Food Chemistry, 59, 7985-7991. https://doi.org/10.1021/jf201323x

Nguyen, H.K., Nguyen, D.H., Le, N.D.D. and Nguyen, C.H. (2016). Effect of soaking chemicals and germination condition to the biosynthesis of GABA 
of IR50404 variety at pilot plant scale. Can Tho

University Journal of Science, 2016, 59-65.

Park, J.Y., Lee, S.K., Choi, I.D., Choi, H.S., Shin, D.S., Park, H.Y., Han, S.I. and Oh, S.K. (2018). Korean Journal of Crop Science, 63(4), 304-313.

Ramezanzadeh, F.M. (2000). Effects of microwave heat, packaging, and storage temperature on fatty acid and proximate compositions in rice bran. Journal of Agriculture and Food Chemistry, 48, 464-467. https://doi.org/10.1021/jf9909609

Rebolledo, O.R. and Dato, S.M.A. (2005). Postprandial hyperglycemia and hyperlipidemia- generated glycoxidative stress: its contribution tho the pathogenesis of diabetes complications. European Review for Medical Pharmacological Science, 9(4), 191-208.

Roohinejad, S., Omidizadeh, A., Mirhosseini, H., Rasti, B., Saari, N., Mustafa, S., Yusof, R.M., Hussin, A.S.M., Hamid, A. and Manap, M.Y.A. (2009). Effect of hypocholesterolemic properties of brown rice varieties containing different gamma aminobutyric acid (GABA) levels on SpragueDawley male rats. Journal of Food, Agriculture and Environment, 7(3-4), 197-203.

Shallan, M.A., El-Beltagi, H.S., Mona, A.M., Amera, T.M. and Sohir, N.A. (2010). Effect of amylose content and pre-germinated brown rice on serum blood glucose and lipids in experimental animal. Australian Journal of Basic and Applied Sciences, 4 (2), 114-121.

Wahjuningsih, S., Haslina, H. and Marsono, M. (2018). Hypolipidaemic Effects of High Resistant Starch Sago and Red Bean Flour- based Analog Rice on Diabetic Rats. Materia Socio Medica, 30(4), 232239. https://doi.org/10.5455/msm.2018.30.232-239

Yaylayan, V.J. (2003). Recent advances in the chemistry of Strecker degradation and Amadori rearrangement: implications to aroma and color formation. Journal of Food Science and Technology Research, 9(1), 1-6. https://doi.org/10.3136/fstr.9.1 